\title{
Perspective
}

\section{New Insights into "The Bignetti Model" from Classic and Quantum Mechanics Perspectives}

\author{
Enrico Bignetti, MD* \\ Professor of Biochemistry and Molecular Biology, MD (retired), University of Parma, Italy
}

\section{*Corresponding author}

Enrico Bignetti, MD

Professor of Biochemistry and Molecular Biology, MD (retired), University of Parma, Italy; Tel. +39 342 8066908; E-mail: Enrico.bignetti@unipr.it

\section{Article information}

Received: June 16 ${ }^{\text {th }}$, 2018; Revised: June 28 ${ }^{\text {th }}$, 2018; Accepted: July 12 ${ }^{\text {th }}, 2018$; Published: July $30^{\text {th }}, 2018$

\section{Cite this article}

Bignetti E. New insights into "the bignetti model" from classic and quantum mechanics perspectives. Psychol Cogn Sci Open J. 20I8; 4(I): 24-35. doi: I0.17I40/PCSOJ-4-140

\section{ABSTRACT}

\section{Summary}

Years ago it was proposed a human cognitive model (TBM) that foresees two compulsory phases (ACTION and COGNITION). The so-called "voluntary" action is decided and executed by an unconscious activity of the mind (ACTION); the gained experience is then elaborated and memorised by the conscious mind (COGNITION). The thought of being an independent Self with free will (FW) is considered by many soft- and hard-sciences an illusionary thought of the mind, though it is a primary individual belief for carrying out COGNITION. This work will investigate this apparent paradox; in particular, it will be put forward for consideration the hypothesis that Self and FW are illusions appearing at the early stages of human life as the outcome of a "primary"stable COGNITION. This believes will be reinforced by further experience gained during the whole life. A second aspect of this work regards the possibility that the mechanism exhibited by TBM (in both phases, partially or entirely taken) might be explained by Quantum mechanics. So, micro and macroscopic events of ACTION and COGNITION will be dissected in order to distinguish the processes that are elaborated by means of plain, biophysical mechanism, i.e.that obey to forcesof a Newtonian field, from those that potentially obey to Quantum mechanics. Interestingly, when it will be argued about the probabilistic-deterministic law of Cause-Effect, a pillar of TBM's COGNITION, the question of incompatibility with Quantum-mechanics seemed to rise, as if that the Newtonian mind might ultimately get the better of Quantum-mind.

\section{Keywords}

The Bignetti Model (TBM), Free Will (FW), Self, Toddler, Classic physics, Quantum mechanics, Cause-effect.

\section{INTRODUCTION}

Since long ago the metaphysical and philosophical discussions on determinism and the questions whether free will (FW) were really necessary for action - decision-making were intriguing. ${ }^{1-7}$ Travelling through different latitudes and longitudes, the author came to the conclusion that Self and FW are necessary illusions to cognition; then it was elaborated a self-consistent model of human cognition, namely "The Bignetti Model' (TBM) (see appendix). ${ }^{8-17}$ TBM is basically made of 6 compulsory steps divided in two phases: ACTION \& COGNITION (see Figure 1).

ACTION principally explains how the so-called "voluntary" action is decided and executed by an unconscious mind (UM)

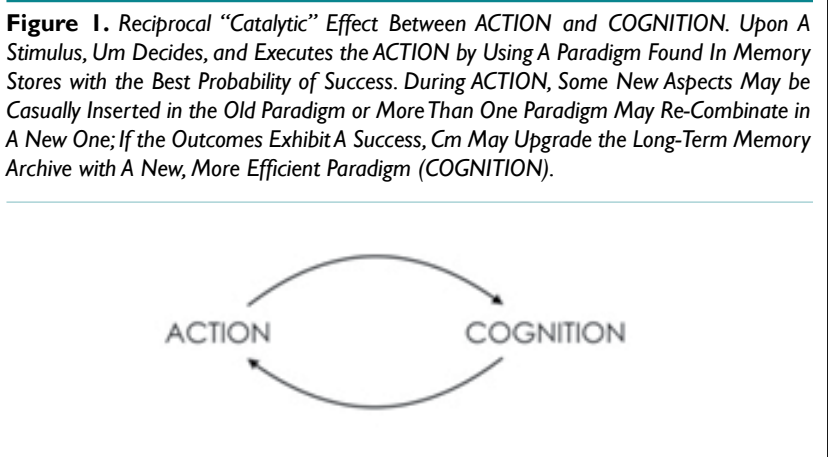

in response to a stimulus. To this aim, UM looks through memory 
stores to find a paradigm uploaded in past experiences that might have the best probability of success. COGNITION principally explains how the mind can learn and memorize a basic skill, a behavioral paradigm or a superior knowledge by means of the individual experience gained in the course of present ACTION. Ideally, at born, the individual mind may start like a tabula-rasa or at a minimum level of knowledge; then, knowledge grows up to saturation, according to a hyperbolic learn-trough-experience function (LTE). The more a stimulus is repeated, the deeper will be the skill on how to react positively to that stimulus, up to a maximal behavioral efficiency. ${ }^{16}$

As one can see from TBM the pillar of cognition is that Conscious Mind (CM), elsewhere indicated as the Ego, ${ }^{14-15}$ works like an inner witness that deludes itself of having freely decided the actions and self-attributes a prize or a punishment depending on the degree of success of the action outcomes. Therefore, cognition stands principally on the illusion that the action - decision-making is made possible by the existence of Ego's FW (note that the kind of FW to which we always refer is the one cited in Stanford Encyclopedia of Philosophy). "Free Will is a philosophical term of art for a particular sort of capacity of rational agents to choose a course of action from among various alternatives". ${ }^{18}$ Moreover, the idea of possessing FW confers Ego the action responsibility, so that both reward and blame are motivational self-attributed incentives that foster learning and memory processes (COGNITION) (by analogy see Skinner and classic Operant conditioning). The knowledge upgrading in short- and long-term memory archives, i.e. the day-by-day experience's gain, will provide new skills for further action. This upgrading is carried out by means of alearning-through experience process (by analogy see Bayes' information theory ${ }^{16}$ by the Ego (see Figure 2)). So far, learning-through-experience (LTE) mechanism proposed by TBM have been theoretically elaborated on the basis of behavioural neuroscience.

Figure 2. "And The $8^{\text {th }}$ Day Man Invented the Ego" (Taken from the Italian "Settimana Enigmistica", N. 4454, 3/Ago/2017).

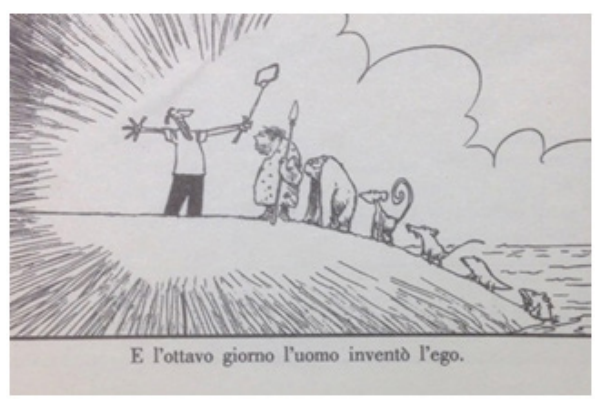

Here, an important work issue is that the basic ground of TBM is the idea that intentions, i.e. action-decision making deliberated by the mind, is causally effective in the physical world, psychic and material. Recently, Bignetti et al. have carried out some experiments of classic psychophysics to test TBM; the data could be easily interpolated by rational curves derived from a mathematical model that is compatible with TBM. ${ }^{19-20}$ The first psychophysical experiments are not enough to consider TBM's theory validated. A more appropriate analytical method (e.g. fMRI) should be applied to a better localization and timing of brain areas engaged in AC-
TION and COGNITION. In the meanwhile, it was also realized that TBM theory implies the existence of a psychic force which is not acknowledged in classical physics; that force exerts a causal influence on the brain and, through it, on other bodily organs, as a result of which the total momentum energy of thebrain is changed. To this concern, what bothers us is not the ACTION which is made by UM in response to an external stimulus; this action - decision-making exerts a physical-chemical force by reproducing a physical-chemical paradigm already present in memory stores. Since it is the result of a physical intention and not a quantum intention it is itself made of physical matter; then, it is plausible that it might be causally effective in the physical world. Rather, TBM's transition from ACTION to COGNITION that seems to imply an illogic jump, should be concerned. In the right moment that ACTION is occurring, Ego self-attributes the action responsibility, thus evaluating that ACTION on the basis of what was good or what was bad, with respect to a-posteriori expectations. This learning process by which COGNITION intervenes first is a mechanism that transforms a neurochemical signals (matter) into a psychic signal (knowledge). Then, this psychic information is transformed again into neurochemical signals to be used to upgrade memory stores. Therefore, the main concern has been how conscious mind can manage a psychic information and then, how that information can be converted again into a neurochemical signal in memory stores? Up today, TBM has never taken into consideration that this jump is incompatible with a classic Newtonian perspective, so that it might rather involve a quantum mind.

\section{THE FURTHER INSIGHTS INTBM UNDERTHE PERSPECTIVE OF A CLASSIC NEWTONIAN UNIVERSE}

\section{The Thermodynamic of Thinking Process:}

In "The continuity of mind", Spivey ${ }^{21}$ clearly explained how mind never stops the thinking process. Attractor basins resonating within neuronal networks generate force fields; so, the thinking process coded by electrochemical signals moves from one network to another attracted by these basins, like a caravel sailing at the mercy of the wind. The information content is influenced by the nature and the proximity of the basin. According to this mechanism, a thought that seems full of sense does not come completely to an end; yet, it leaves a feeble trace that is gently pushed towards new attractors under the influence of close force field; along its travel, a new attractor might supply this trace with a new source of energy/information, giving rise to a renewed thinking process. Concluding, one can deduce that, the continuity of mind in Spivey's perspective is, on the one hand, compatible with the generally accepted view that mind activity has evolved towards a statistic-probabilistic computation mechanism. On the other hand, the caravel, while meeting up with the future lands, never has the mishap of a calm sense. Moreover, a thought produced outside a brain, i.e. outside the reasoning flow of a brain, cannot be inculcated in it, unless preliminary sensory inputs predispose adequate attractors

Actually, it should be concerned that when a thought (caravel) runs away from an attracting basin and points to another one has not the same content as before otherwise the process could come into conflict with thermodynamics. As already 
explained in a recent work, ${ }^{17}$ by saying that the information implicit in a thought is totally manipulated by attractors instantiated behind and ahead, one should admit that the mind can never step aside the flow of its thoughts. In conclusion, the thinking process does not leave any room to the kind of creativity and autonomy that people presumes to possess; serendipity, intuition or any other psychic ability always springs somewhere from a thinking flow that is solicited by some hidden stimuli. Moreover, although incompatible with true FW, this mind might well delude itself to possess it: a lucky illusion, one would say, since, on that illusion the pillars of COGNITION can stand on.

Almost the same inferences could be drawn by investigating the thermodynamics of the thinking process at the molecular level. ${ }^{8-11,16-17}$ By considering the pattern of a thought as a free energy profile of a catalyzed reactions, it was concluded that a thought can be considered a compulsory sequence of reactions "catalyzed" by a well-organized network of membrane pumps, enzymes, channels, etc., whose molecular products function as substrates for the next ones in the reasoning flow. The reactions driven by neurons (and neuronal networks) follow the path which is favored by the arrow along with the parallel degradation of molecules of high chemical potential (like ATP or GTP or others) can dissipate Gibbs Free Energy (see Figure 3); from a thermodynamic point of view,

Figure 3. "Reaction Coordinate and Energy Profile of A Thinking Process According to the Idea That A Thought Is Produced by A Series of Mind Catalysed Reactions. The Apparently Chosen Pathway of A Thought Is Indeed Conditioned By Thermodynamics and, In Particular, by Gibbs Free Energy Maximal Production. Moreover, the Figure Tries to Represent How An Information Can be Shared by A Net of Minds Interconnected. to This Aim, the Thinking "Products" $X n$ of Mind $X$ are Transferred as Substrates to Mind Y,Then to Mind Z and So Forth (Taken from "La Dissacrazione Della Coscienza, Bignetti, 200I).

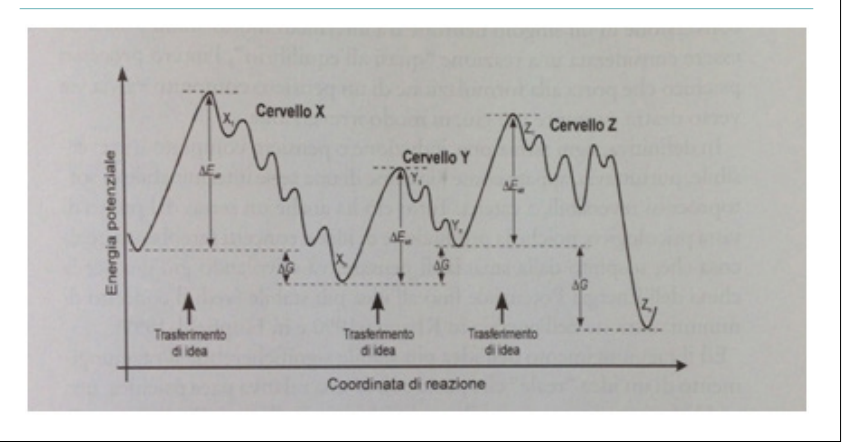

a thought will never end unless it will fall into a basin with molecules with very low energy content. In analogy withthe caravel that willreach a calm see, a thought might conclude is travel and find a completion in as table situation, for example when is archived in longterm memory store..$^{22}$ By means of the analogy with a Biochemical system, the author theoretically investigated nature and function of Self. Then, the author's hypotheses was compared with various theories on the personal identity (PI) found in the wide landscape of soft- and hard-sciences. In accordance with many Western and Eastern philosophers, ${ }^{23-36}$ it was concluded that since mental activity is conditioned, deceptive and often incorrect, the conviction of possessing FW may be conditioned, deceptive and incorrect as well.

\section{Motivations and Rewards in TBM:}

Unlike the numerous theories and models about the mechanism of human cognition till now present in the literature, TBM is really the unique one that reconverts FW-illusion into an essential ingredient on which cognitive processes underlie. To validate this hypothesis, recently, Bignetti et al. ${ }^{19-20}$ carried out press/no-press psychophysical experiments by using salted and sweet foods images (respectively "press" and "no-press" cues) that were projected onto a computer screen. Upon cue recognition, subjects had to decide whether to press or not, as fastest as possible. By this means, subjects' decisional ability could be correlated with the shortening of the reaction times (RT). The results showed that subjects' ability increased hyperbolically as a function of repetitive trials, up to a physiological limit, thus exhibiting a typical learning-through-experience (LTE) function. Moreover, the introduction of different "press" cues in the same test reduced the slope and the limit of the hyperbole, thus working as distractors. Most probably, each novel salted cue had to be recovered from Long-Term-Memory, thus delaying the overall response. On the contrary, neither semantically different images (like a car or others) nor sweet cues did play a negative effect. Our cognitive test was designed to monitor an action-decision mechanism within a homogeneous population of University students that offered gratis their commitment. It is known that personal experience lived with a full subject's motivation is required in tests that are based on learning new skills, deepening the knowledge, reinforcing opinions, upgrading long-term memory content, etc. Among the reasons underlying this process, great importance is given to reward and punishment. Schultz ${ }^{37}$ has divided rewards mainly in two classes: "primary" (e.g. food and beverages that satisfy an urgent need of substances for survival) and "non-primary" (e.g. those substances that enhance the function of primary rewards, that ensure gene propagations, enhance the chance of reproduction and favour evolutionary selection). Primary rewards are also considered homeostatic: for instance, food given as a reward after a test can be considered a primary homeostatic feed-back since it erases the urgent stimulus of hunger. His subdivision seems to be compatible with the finding that the two mechanisms travel along two different anatomical pathways in SNC. Actually, no cognitive ability test in humans uses primary rewards; in this case, the rewards can be usually classified either as "intrinsic", like the achievement of an inner, emotional or intellectual pleasure, or "extrinsic", like tangible prizes, money or so. Some psychologists (the author agrees with them) consider that tests made by volunteers, being moved just because it is inherently enjoyable and not because merely conditioned by win money, leads them to engage in exploration and other behavioural tests. According to the literature, the development of broad competence can be better favoured by activities driven by curiosity in the absence of explicit reward, rather than being directed to more external goals. ${ }^{38-39}$ This attitude represents a great difference with respect to machine learning that may not cope flexibly when facing new problems. A first hypothesis we drew from these data, was that subjects' ability increases from trial to trial because the paradigm for a correct action - decision-making is upgraded on the basis of the degree of success of the action outcomes. According to TBM, a successful action outcome might work as an 
intrinsic reward for the improvement of cognitive ability. This ex-post upgrading undergoes a mechanism similar to information processing and upgrading in Bayes' information theory. ${ }^{40-42}$

As already discussed elsewhere, ${ }^{15}$ Tolman's "Cathexis" ${ }^{43-44}$ represents the knowledge of what could occur in the presence of a stimulus; then, one could predict the degree of success of his own actions in response of a given stimulus if he has been already engaged in it or in a similar one in the past. Unlike Pavlov, Tolman claims that an unconditioned stimulus cannot automatically trigger a successful response; the incentive value of a voluntary action is instantiated in the motivational system as a post-adaptive mechanism. In other words: every time we act, we have the opportunity to find out our incentives and test their relative efficacy; thus, we may not only deduce something new about the stimuli, but we may also evaluate the adequacy of our motivations with the reaction to it. Then, cognition and motivations both depend on action outcome, so we can learn how to finely tune the system for the future. ${ }^{9}$ Experiments performed in rats demonstrating that the rats failed to drink sweet drinks when feeling thirsty for the first time due to sudden water deprivation, confirmed the Tolman's thesis. ${ }^{45-47}$ Cathexis may perfectly explain also the results of our press/no-press tests. According to TBM, the cognitive performance is determined by the outcome of the action itself; in fact, depending on the degree of success of every action, the subject self-attributes a prize or a blame as incentive values on the basis of which he feels psychologically gratified. Then, one may infer that when the knowledge in mind is still low (i.e. the mind is like a "tabula rasa"), action-decision mechanism is mainly driven by a probability-based reasoning leading to a low success so far; while, actions with high probability of success do occur in expert agents since UMs' choices converges towards a single deterministic protocol. In conclusion, human cognition proceeds trial after trial to acquire high-levels of knowledge by means of a post-adaptive mechanism; the probabilistic-deterministic shift of the couple ACTION-COGNITION in TBM is the most striking examples of the Darwinian evolution of knowledge, ${ }^{9,11}$ thus in contrast to the Lamarckian-type of cognition theory based on the mirroring of other's actions, proposed by Ramachandran. ${ }^{48}$

An interesting evidence that emerges from this investigation is that an agent can improve target precision and shorten the timing of execution of a voluntary action upon repetition of the same stimulating experience (let's imagine a tennis player who spends his life training himself in a tennis court, or compare a beginner driving a car with an expert). Moreover, it is quite clear that to improve a cognitive performance, the same original paradigm must be repetitively exploited; this is possible only if the stimuli share common semantic features (graphic, verbal musical, etc.). Conversely, in case the different stimuli do not belong to the same semantic category (the so-called "distractors") then UM must adopt different decisional paradigms corresponding to new targets, every trial; this necessary impairs agent's LTE either by opposing to RT shortening, by introducing several mistakes on the target recognition and by incurring in paradigms mismatching.

\section{Why do People Believe so strongly in FW? A TBM-Based Hypothesis:}

When people proudly claim to use FW, that claim does not coincide with the right moment of the true action - decision-making. It's odd that people will never ponder that the explicit belief in FW isn't synchronized with action - decision-making; in fact, the thought of possessing FW is per-sea complete action that appears in mind independently on the action.

On the one hand, as it was discussed in preceding papers, the 3 rd-person and the $1^{\text {st }}$-person perspectives (3PP and $1 \mathrm{PP}$, respectively) on the nature of Self and FW cannot coincide since, they start at different times, originate from different premises and follow different attractors. Then, it is almost impossible that 3PP idea of Self and FW as illusory by-products of the mind ${ }^{12-14}$ could be instilled into a 1PP mind; instead, on the basis of religious faith, it is much easier that $3 \mathrm{PP}$ and $1 \mathrm{PP}$ minds may coincide on the believe of the existence of a Soul-inhabited Self. In general, if one excludes religious motivations, Self and FW are differently perceived by $1 \mathrm{PP}$ and $3 \mathrm{PP}$. 3PP assumes an objective point of view when commenting both others' actions and one's own action, thus standing on a rational and detached mode; furthermore, a scientific view point of $3 \mathrm{PP}$ usually denies the existence of a Soul-inhabited Self. ${ }^{49}$ Conversely, typical of $1 \mathrm{PP}$ is the prejudicial, affective mood that describes one's own actions as the endeavour of a FWequipped Self. ${ }^{50}$ So 3PP can unveil the psychological motivations that lead to $1 \mathrm{PP}$ but not vice-versa. This mechanism better concerns with TBM hypothesis according to which Self- and FW-illusion might rise from a fictitious experience of the mental faculties. ${ }^{9-12,14-15}$

As a matter of fact, due to reiterated voluntary actions, cognition is progressively improved in accordance to the expectations; this ex-post evidence reinforces the individual conviction of possessing FW. In addition, these practical conclusions have suggested us the reasons why the idea of possessing FW is so strongly bound to people.

However, one thing is still obscure. According to TBM, ACTION is decided and executed by UM so that the conscious idea of being a Self with FW will never steer an action but will function as a necessary basis for COGNITION; so, the questions still unsolved are: "Which is the psychological origin of a so strong belief in the existence of a Self with $F W$ and how does it rise?" The rise of a personal identity (Self) in mind was tentatively ascribed to the very initial steps of life, possibly, with the intra-uterine experience. At this stage, the skin splits the word into inner and outer domains and the brain is on the inner side of the two; this asymmetric localization determines the rise of a $1 \mathrm{PP}^{8-9}$ As it regards the question on FW, the arousal may coincide with Toddler's age, i.e. the first 3 years of a child that are characterized by the most fruitful phase of social and affective interactions with the environment. This phase is known as crucial for children's grow since it is characterized by the greatest development of cognitive, social and emotional stage in humans' life. ${ }^{51-52}$ In most cases, tantrum is associated with frustration, anger or other emotions that children do not know how to deal with. However, tantrums are one of the most common forms of problematic behavior in young children, but tend to decrease in frequency and intensity as the child grows older. The toddlers' critical age, interests us mainly for two milestones: 1) the first one is the awareness of a Self; at about the age of 1-2-year-old, a child 
will begin to recognize herself/himself in a mirror as a separate physical being; the presence of her/his own PI with thoughts and actions are early perceived; 2) The second behavior should be considered, is the toddlers' phase of "Bossy" with parents and caregivers; orders them around and the phase of "No", i.e. the refusal to with stand their commands and rules; this phase reveals a dare to dictate their own will upon the others' one (https://www.motherforlife.com/baby/13-36-months/psychology/1392-the-no-stage. thtml; http://www.parkchildcare.ie/how-to-deal-with-the-nophase.html). Up to us, this preliminary sense of Self that possess a full or at least a conditional FW, may represent the "go" step for a TBM-based cognitive grow that will self-reinforce whole life ahead.

\section{Duality or Not? The Answer comes from The Far East:}

In a Hindu text one can read: “... Ganesha sits on the psychic lotus of the Muladhara Chakra, the ganglia of nerves at the base of the spine of man which governs time, matter and memory...". As the aspirant worships Lord Ganesha, he slowly enters the Hindu religion. Once this connection is firmly established he has gained divine protection. But he loses one thing...that great Western free will to which everyone aspires and which audaciously claims, "I can do whatever I want to, whenever I want to. Nobody is going to tell me what to do?"--this so-called free will is lost. Yet, it is not a great loss. Man's own personal will, his free will, is a feeble and insignificant force when compared to God's will. He can unweave you from your karma, simplifying and purifying your life. This happens once you have established a personal relationship. Soon thereafter changes will probably begin to happen in your life, and you may go through difficult times. Don't worry if that happens. Know that at such a time you have surrendered your free will, and now it is God's will that guides your life" (https://www.himalayanacademy.com/media/books/what-is-hinduism/web/ch23a.html). It is clear that this Hindu sage refutes FW, at least its folk meaning, since he considers the fate in God's hands a safe travel to the destination; incidentally, not believing in God, the innermost meaning of this message might appear as a sort of glorification of "determinism"; then, either you will not accept the leadership of this special "driver", thus suffering the pain of an everlasting conflict, or you inwardly accept it so that you will definitely become an enlightened man. Different Hindu sages share this position: either you don't see that FW is an illusion and you delude yourself to be the driver of your own car but or you escape from the mental restrictions and accept that your personal Self might dissolve into the Universal Self. In the first case, the mind is typically dual: me and you, brain and mind, body and soul, etc.; then, perceiving yourself dissociated from the rest of the world, your life will be a painful, heavy sacrifice and an inner conflict. In the second case, recognizing that mental limits are detrimental to the Self, you perceive to belong to a bigger, unique Reality, in peace with all. In Hindu philosophies of Vedic tradition there are two orthodox Darśana that describe well the two situations: Advaita and Samkhya. In principle, both of them consider the Vedas as a reliable source of knowledge; however, Advaita admits Ishvara (God) as the final cause of all. Moreover, an individual " $i s$ " the absolute Self or Awareness, the Cosmic Spirit (also known as Brahman); though Self is an empirical reality, it is not perceived because of Maya (illusion), that prevents the unveiling of what it is; if an indi- vidual cannot find the way of unveiling our ultimate divine nature (to this aim some Advaita schools accept the existence of FW), she/he will never escape from Sasāra, i.e. from the pains of ignorance, impulsiveness and inertia due to a cyclic dyeing and rebirthing in the world of Maya. On the contrary, Samkhya is considered strictly a dual, atheistic philosophy since admits the existence of two entities governing the world without any reference to God: Prakriti (the active matter; a sort of Natura Naturans that moves and makes everything) and Purusha (the inactive consciousness that embody the apparent Self or Ego). Advaita and not Samkhya gained high popularity in the west and middle East; most probably, because it sounds in tune with the doctrine of the three major monotheistic religions, standing on the belief on a unique God and on the existence of human FW (for analogous reasons, Buddhism, a Hindu heterodox philosophy, shared the same success as Advaita). However, on a closer inspection of renowned philosophic sources, Samkhya is neither "strictly" dual nor atheistic. At first, it might be worthwhile to cite a comment on Bhagavad Gita (one of the maximal expression of Hindu philosophic literature) written by Sri Aurobindo, an "enlightened" philosopher and mystic; ${ }^{53}$ he well explains that Purusha deludes to be Prakriti: he dresses her clothes and takes the merit of her successful actions, and embodies her unstable personality by saying "I am this, I am that", in his stead. In truth, Aurobindo claims that Prakriti is playing the role game of an aware witness that makes nothing to undermine the pretentious and arrogant Purusha's role (i.e. the human Ego). The stands on the reason that if the frivolous personality of Purusha should be punished, the subject might fall down into a tamasic, depressed inaction, thus threatening life's stability. It is clear that Aurobindo, does not want to attribute Prakriti a Divine nature though he seems allusive that the cosmic law governing the world derives from a unique energy source like that. The fact that Samkhya does not explicitly mention God is not necessarily the proof of its atheistic nature; the existence of God or supreme being is not directly asserted, nor considered relevant by the Samkhya philosophers. For instance, according to the vivid image of Radhakrishnan, ${ }^{54}$ the inseparable couple Purusha and Prakriti carries on a unique design of the Universe, like a lame on the shoulders of a blind; elsewhere, Prakriti is compared to the Aristotelian God. Another example of orthodox Darśana that does not explicitly mention God, is Yoga. Ancient Yoga schools encourage people to experience Ishavara (the Supreme Soul) inside us by means of practice and meditation and not only by the mind, quoting famous Patanjali's "Yogas chitta vritti nirodha". In conclusion, after a brief psychological-sociological travel through some Hindu Darśana, the final message one can draw is that it's up to her/him to rely completely or not on human mind; if so, by faith in it, she/he must believe also in God and in FW. Otherwise, the search of a cosmic Self must be carried out as a whole, i.e. to see the problem under a holistic perspective an individual cannot limit our glance from inside-out our mind. ${ }^{8}$ To this regard, the message of the enlightened philosopher and mystic Krishnamurti merits consideration. He was born in India, a land where mental introspection is thoroughly exercised to discover the limits of the mind and find the way to escape from them. His constant search of truth and curiosity of life gave him the opportunity to approach the secret maze of human mind from several irrational and rational points of view. So that, at the beginning of his life, he made wrong choices; however, once enlightened, he gave 
a strong, public talk to refuse any sort of psychological conditioning, any allegiance to any nationality, caste, religion, or philosophy. Therefore, he spent the rest of his life travelling the world publicly restating his conviction: "I maintain that truth is a pathless land, and you cannot approach it by any path whatsoever, by any religion, by any sect". With regard to FW, he gave in 1978 a famous conversation with Buddhist scholarsin which he analyses where originates the idea of FW in human mind. ${ }^{25}$ The conclusion was that FW is a desire of Ego; therefore, there isn't an action really free if it originates from Ego. If Ego and his memory content poses fences to the thinking process, the mind is conditioned; so the action cannot be perceived as a whole. In few words, Krishnamurti was used to affirm that our present action is a revival of our past; a true inner revolution is to see this vividly, i.e. realize the maze into which thoughts are always entrapped is the inevitable premise of our thinking process. Mind that trusts in his thinking mechanism is conditioned to a dual and does not open to a whole compassion and enlightenment.

TBM has been elaborated by positively considering many of the concepts above resumed. At first, the personal identity (PI) of a subject entirely stands on its memory content, so that when PI intervenes in an ACTION, subject's memory content is engaged and, then, up-dated on the basis of a new experience, by COGNITION. The so-called "voluntary" reaction to a stimulus, i.e. ACTION, is decided by UM; be either rationale or emotional, ACTION is elaborated on the basis of a concrete, coherent paradigm found in memory stores. The way by which the paradigm is chosen stands on a criterion of probable affinity or identity with past situations. At second, according to Western philosophies, mind as well as the most sophisticated technology that mind can conceive, are intrinsically limited; mind's limitations though, do not exclude there might be still room for experience-based cognition. Critical functions such as inference, induction or correlation ultimately manage our memory content; if memory plasticity could not be accomplished, people would still live at the era of the caves. At third, UM and CM, i.e. the two interpreters in TBM of ACTION and COGNITION, respectively, remind the roles of Prakriti and Purusha in Samkhya. UM makes the decisions and actuate the actions while the awareness comes a bit later with $\mathrm{CM}$; since $\mathrm{CM}$ hasn't a retrograde vision, thinks to be the responsible agent, thus deluding itself to be the action-decision maker instead of UM. To this one may comment that, according to 1PP, ACTION and COGNITION are attributed only to a unique actor in the scene, i.e. to CM; however, soul-inhabited Self is a necessary pre-requisite so that FW and the associated rewards may play a primary role in COGNITION. Therefore, according to the $1^{\text {st }}$-person perspective, a dual vision of the world emerges. On the other hand, duality appears also from the 3PP of TBM: ACTION and COGNITION are figured out as a dualistic mechanism based on different interpreters, such as the deterministic power of the nature (UM) versus the subjective illusions of possessing Self of FW (CM). Actually, according TBM, the duality between $1 \mathrm{PP}$ and $3 \mathrm{PP}$ seems to be only apparent, but it works, at least from a cognitive point of view. As mentioned above: "...In truth, Aurobindo claims that Prakriti is playing the role game of an aware witness that makes nothing to undermine the pretentious and arrogant Purusha's role (i.e. the human Ego). The stands on the reason that if the frivolous personality of Purusha should be punished, the subject might fall down into a tamasic, depressed inaction, thus threatening life's stability". Moreover, on the one hand, a 1PP cannot see this limiting maze that his memory-based mind is constructing around him; on the other hand, the question regarding the $3 \mathrm{PP}$ is even more intriguing: is there anybody who has the authority to tell us this perspective is really true? To answer, one should keep in mind that any thought resonates within a mental maze, i.e. within a limited space of work that, in addition, is obscured by Maya. In conclusion, TBM is a description of what the intimate mechanism of cognition might be, with a practical spin-off in science and ethics but it does not wont to support any philosophical or religious discourse on the "truth". Personally, I think that TBM is perfectly compatible with Krishnamurti's teaching, in the sense that the thinking process is our past in action. Except for practical purposes, our mind is intrinsically dual; conditioned by its own physical limits, it will never be able to unveil what we really are.

\section{TBM DISSECTION TO EXPLAIN QUANTUM MECHANICAL ASPECTS}

With the advent of modern physics, the old "dualism" tries to reinvent itself by introducing both in physics and then in philosophy, a new list of "apparently" opposing categories, such as "quantum vs classical physics", "reality vs. appearance", etc. In particular, the old Descartes' dualism "brain vs mind" (or "matter vs mind") disguises in "matter vs wave", a new couple better fitting Quantum physics and Relativity. Actually, the members of the new sort of dualism are no longer mutually exclusive or antagonistic, rather they are complementary. This inference can be understood assuming that the image of a " $r e d$ " object is perceived by our eyes and then projected on the brain vision area, so that we can explicitly manifest to see a "red" object. The mental awareness of " $r e d$ " is a "qualia". This term means a consciousness state that is evoked in the mind, in front of a "red" object. The meaning of Qualia goes back to classic Greek philosophers, but the term has latin origins; then, it is discussed by the empiricist Locke; recently, it has raised controversial discussions between Searle and Dennett. The word " $r$ d" unequivocally evokes the qualia of "reddiness" in all people and not that of "whiteness" or "bluishness", etc. Other symbols referring to the colour "red", likewise a graphical image or the word written in Braille, etc., can be equally used for that quale; though, the corresponding stimulus does not necessarily produce the same biophysical activity in all minds. In conclusion, the travel of our sensation starts from the physical image of a macroscopic red object; then, after a transduction of the image into a series of chemical-electrical impulses, this information crosses a virtual brain-mind barrier thus becoming a mental idea. If a red object has been already perceived in the past, then the same physical-chemical trace that triggers that mental idea of the colour red and not of another, can be easily recognized. In the philosophy of mind, qualia are non-physical entities is; their existence might rise from the idea of an ontological dualism that divides researchers in different schools. ${ }^{55}$ By accepting the existence of non-physical entities, further debates as to their inherent natures and their position relative to physical entities point to the acceptance of a dual mind, intrinsically separated. Up to us, the old-fashioned dualism of the couple "brain vs mind", seems instead to cooperate by exchanging compatible forms of energies. Therefore, we can grasp one of the major precept of the modern physics: the distinction between subject and object does not make any 
sense, i.e. object and subject are a unique reality; the distinction observed within the coordinates of Classic physics is only appearance according to Modern Physics. Sir James Jeans ${ }^{56}$ wrote: “... This dualism of appearance and reality pervades the history of philosophy, again dating to Plato. In a famous parable, Plato depicts mankind as chained in a cave in such a way that they can look only the wall which forms the back of the cave; they cannot see the busy life outside, but only the shadows the appearances which objects moving in the sunshine cast on the wall of the cave. For the captives, the shadows constitute the whole world of the appearance the phenomenal world while the world of reality lies for ever beyond their ken. Ourphenomenal world consists of the activities of matter and photons; the theatre of this activity is space and time. Thus the walls of the cave in which one feels imprisoned are space and time; the shadows of the reality projected on the walls by the sunshine outside, are the material particles moving against a background of space and time, while the reality outside the cave which produces these shadows is outside space and time...". The idea that the distinction between subject and object is not real, has profoundly shaken not only people's common sense but also the scientific concern. To understand the reality, a new revolutionary approach to scientific investigation compatible with a non-dual knowledge is needed. To this regard, Schrodinger ${ }^{57}$ commented that if modern philosophy would get into a more intimate modality of non-dual reality knowledge, it should deny subject-object distinction; even though, just for practical purposes, we should maintain our belief in it for a useful reference in everyday life. The Quantum physics claims that a subject that pretends to measure an object, is altering so that that reality is the subject's object. Moreover, according to the indeterminacy law, we cannot predict object's location in a Newtonian space by measuring the speed and vice-versa. ${ }^{58} \mathrm{On}$ this basis, some authors have inferred that FW is intrinsically real since a deterministic correlation between a voluntary intention and the action outcome is nullified by the intrinsic indeterminism. To this statement several comments can be made:

\section{Word is Determined or Not? In Other Terms FW is Necessary or Not?:}

One of the most intriguing question regards whether the word is determined or not, in particular whether the cause-effect relationship holds in human behaviour. According to TBM, memory stores contain a series of tailor-made paradigms through which UM may look for the one to be used foractual ACTION; the most affine paradigm to UM's needs will obviously be the one with the highest probability of success. So, the right paradigm to be used, might correspond to the biophysical attractor that might condition ACTION at best. Upon repetitive stimulation, that paradigm can be progressively adjusted to give the maximal probability of success in the future; so that the next ACTION will become totally automatic and conditioned. Typically, this progression is at the base of the learning trough experience (LTE) mechanism. A consequently question thatderives: "If COGNITION is determined by post-adaptive experience-based learning, why do we need believing in FW?'. To make TBM (LTE) possible, our mind has excogitated a mechanism by which the illusion of possessing FW plays a functional role in cognition. Sometimes quantum scientists claimed that in sub-microscopic word scale natural processes are not determined due to the indeterminacy law; for extension, it was inferred that FW might exist so that we cannot predict the future. Our rebuttal to this is that sub-mi- croscopic events do occur in the biophysical word that underlies mental processes; however, mind is concerned of macroscopic events so that an individual is totally unaware of the indeterminacy effects on sub-microscopic word. The apparent paradox is that the macroscopic scenario of the real that opens in front of everyone's eyes, stands always on classic physical chemical laws, though this real hides a sub-microscopic word with quantal properties. As a matter of fact, thismay occur since every minimal detail of the real word a subject can see and measure, is determined by a large mean of microscopic events varying in space and time; this mean appears stable and predictable, i.e. it is probabilistically determined and easily interpretable by the subject. ${ }^{59-60}$ This hypothesis holds also for the "macroscopic cause" (stimulus) of an expected voluntary reaction. If this "cause" repeats, one may gamble that also our reaction (i.e. the "effect") will be always the same... because our mind is conditioned to work in a macroscopic dimension. This inference leads also to conclude that the indeterminacy of which quantum scientists are talking, is absolutely irrelevant from TBM point of view; the FW idea that any individual is strongly attached to when describing his or others' voluntary actions, has nothing to do with law of indeterminacy (see FW definition in INTRODUCTION).

\section{The Cause-Effect Relationship in TBM:}

As said above, the indeterminacy law may be addressed at processes that occur at the sub-microscopic level; this concept may apply to the arousal of sensory stimulations, i.e. when stimuli are striking the neurological apparatus of our brain and then are transduced into inner information. Therefore, the objectivity (if any) of the stimulus is "subjectively" interpreted because the interaction (entanglement) with SNC modify the information we are going to compare with memory content. As exemplified above for the qualia, colour "red" rises always the same "qualid", this means that the objective sensorial interpretation is reliable; as well as the reaction by which we pronounce the word " $r e d$ " or we decide to mix it with "yellow" to get orange, is reliable. In other terms, since outer stimuli cause always the same inner intentions and, in turn, inner intentions cause reliable individual actions, the sub-microscopic indeterminacy that might underlie the macroscopic information processing, does not impair it. Concluding the cause-effect relationship which our thinking process stands on, is safe!

\section{The Randomness Objection of Schroedinger:}

On the other hand, it cannot be demonstrated whether people under the effect of an indeterminacy-based FW would react exactly the same way going back in time, since the Moviola cannot be rewound in order to reproduce the same situation as before. Moreover, according to TBM, people becomes aware a-posteriori of how things are going on, and the illusion of possessing FW arises a-posteriori as well. So that the indeterminacy-based FW that quantum scientists are discussing about, has nothing to do with the FW folk idea that all people delude to possess (see dictionary's citation above. ${ }^{17}$ Conversely, there are scientists who stand against connecting quantum indeterminism with free will, on the basis of Schrödinger's randomness objection: "...voluntary decisions reached after deliberation cannot be compared to chance events...". According 
to TBM, one might feel confident to confute also this objection since it derives from a wrong assumption: what these scientists mean as "voluntary" decisions or intentions, actually, do not derive from the aware instance of CM' will, since UM and not CM is in charge of them. By the way, it's interesting to note howsuch a consistent amount of papers on the principles of Indeterminacy and its possible extension to mind activity and, in particular, to action - decision-making and FW, has been published before the end of $20^{\text {th }}$ century (see the bibliography in Esfeld; ${ }^{62}$ by this time, the advent of papers of Libet and others on the unconscious "Readiness potential" that reliably precedes the self-initiated movement, seems to announce a real revolution in neurosciences. ${ }^{1-3,63}$

\section{What is Classic and What is Quantum in TBM:}

Many hypotheses based on Quantum mechanics, have been proposed to explain consciousness. These efforts have risen strong criticism since, in many cases, they uses the term Quantum somehow far from the "classic" Quantum mechanics; moreover, most of these theories shouldn't be taken as scientifically proven. Quantum mechanical phenomenon as entanglement's brake, decoherence or wave function collapse are proposed to occur during the interaction and measurements of a conscious mind with the environment. ${ }^{64}$ Extending this concept to action - decision-making, Stapp ${ }^{65-66}$ proposes that Quantum waves are reduced only when they interact with consciousness, i.e. only when the agent selects only one decisional pathway for the future action among different Quantum possibilities. According to him, quantum mechanics elevates mind from a causally inert by-product of a determined universe to a "co-creator" of a psycho-physical reality.

Some authors instead, introduced Quantum mechanics in Consciousness studies with the aim of opening visual perspective of mankind on the world. Chopra ${ }^{67}$ claims that the Universe is the example of how Quantum entanglement may link everything thus creating the conditions for consciousness arousal; moreover, Quantum effects of consciousness in medicine may offer a potent healing tool. From a completely different perspective, Bhom ${ }^{68-69}$ proposes to elevate the view on Reality to a higher level of wholeness; to this aim, he proposed the existence of "the implicate order" from which it derives "the explicate order" of the nature as it appears. According to him, the (qualitative) analogy between mind and matter is fairly close so that it provides a way of thinking mind and matter as a wholeness. This brings the human perspective to a connectionist view, i.e. a more coherent understanding of the Reality than is possible in the common dualistic and reductionist view. By the way, Bhom had the opportunity to argue abouthis scientific ideas in various public occasions with Krishnamurti. ${ }^{70}$

According to TBM, ACTION stands on a series of events of biophysical nature, while learning and memory processes of COGNITION stand on psychological mechanisms; moreover, the agent's awareness rises during COGNITION a bit later than ACTION itself. So ACTION and COGNITION do not abide the same physical rules:

a) ACTION is unconsciously driven to react to a change of the environment (inner or outer) in order to remove it or adapt to it; this mechanism of defence or adaptability is typical of biological systems but is also a clear operative example of Le Chatelier's principle, also called "The Equilibrium Law" telling that when any system at equilibrium for a long period of time is subjected to change in concentration, temperature, volume, or pressure, then the system readjusts itself to partly counteract the effect of the applied change and a new equilibrium is established. That principle refers to changes in gradients of macroscopic parameters that influence a system and its environment reciprocally; it predicts the effect of a change in equilibria in many systems such as physics, chemistry, biochemistry, physiology or even in economics. In our case, a stimulus is perceived and is recognized in a time scale enormously larger than light speed; then the confidence of recognition depends on probability it is hardly mismatched by our sensory organs, the experience of a change (for instance, a red object is turned to yellow) the quale "Red". Moreover, UM's reaction to this stimulus (according to "The Equilibrium Law") is elaborated on the basis of a paradigm that has been stored in memory archives on the basis of the previous experience; i.e. as much as possible on the basis of a paradigm that might exhibit the best success probability; that paradigm might be an UM's attractor found in memory stores, that shares the highest chemical-physical analogy with the present situation. In summary, action - decision-making in TBM is an unconscious process that operates in a field of classic Newtonian forces; therefore, Schrodinger's cat paradox ${ }^{71}$ that is usually brought out when discussing about consciousness, does not hold here.

b) In contrast to ACTION, the question on how COGNITION is carried out, requires a more complicate explanation. At first, one should keep in mind that COGNITION must wait any possible information coming through feed-back signals, so that it is occurring a bit later than ACTION and, at second, it cannot have a retroactive sight, though deludes to be responsible of what is occurring at present. Then, by analysing more in depth the overall process of COGNITION and dissect it into further sub-steps, one mightrealize that they are governed by at least by a couple of rules: Biophysical and quantum mechanical.

i. At the beginning of COGNITION, there is a sort of transitory step in which a huge amount of feed-back sensory inputs from the periphery informs CM (the inner witness) on how ACTION is going on. No doubts that this kind of information is of biophysical nature; so, this step does not represent a hard question for a scientist. Actually, what is difficult to explain comes later;

ii. Now, the information perceived by CM in i) becomes explicit either to itself and to anyone else by inner and outer speech, respectively. The questions are:" how a biophysical information may be transduced into a conscious psychological representation? By which mechanism or code is it possible to CM?" Most scientists have not yet answered this question; however, the underlying mechanism reminds to the discussion on the nature and the meaning of qualia; as it happens for the arousal of qualia, likewise the CM's transduction of biophysical signals in a conscious experience, though mysterious, is absolutely reliable. At first, CM undergoes a sort of psychological alienation, making the agent's psyche identifying with a Self. On the one 
hand, this psychological alienation cannot be easily explained simply on the basis of some electrochemical signals buzzing around the grey matter. On the other hand, the hypothesis of a soul-inhabited self is very weak for many reasons; the most obviousis that a hypothesis (or thought) is not mind-independent; moreover, not all cultures in the world agree on it (see above the discussion on atheistic Samkhya and the relationship between Prakriti and Purusha). So, an answer to the hard-question: "What is consciousness?" 72 might be tentatively given first by trying to explain: "Why is there a consciousness?" According to TBM, Self is an illusion needed to foster cognition; its origin might be tentatively attributed either to a psychological mechanism or to a superposed state coexisting with CM, according to modern Quantum physics. If the latter hypothesis holds, some inferences can be made: 1) the mental representation of the reality might arise from the entanglement's brake of a "Quantum Self" with the external world; 2) Ego will arise as an auto-state of the Quantum-Self when this is engaged with outer sensory inputs. Then, the collapse of Quantum-Self function will produce Ego, a virtual psychological entity that will work on behalf of the self in order to bring CM trough the experience-based cognition in two steps: learning and memory; 4) As it regards the learning process, first, Ego believes of having freely decided and executed the action; on this illusion, Ego self-attributes the responsibility of the action (possibly, the sense of self and the idea of possessing FW arise together according to a $1 \mathrm{PP})$. How such a self-concerned $1 \mathrm{PP}$ might arise cannot be scientifically explained; however, it can deduce by means of a 3PP, that Ego and FW illusions must arise in our psyche just in life's moments that are mandatory for COGNITION;

iii. According to $1 \mathrm{PP}$, conscious Self believes to be responsible of ACTION decision and execution; then, it puts in action a critical sense that is, from a cognitive point of view, the most fundamental mechanism leading then to memory storesupdating. By comparing ACTION outcomes with expectations, a good ACTION is distinguished from a bad one by means of CM's critical sense; CM self-attributes the ability of a value judgment made of reward or punishment; though, relatively speaking, both carry on the same didactic experience for the improvement of knowledge. In order to express a critical sense, the incoming biophysical signals must be transduced into conscious matter by means of a functional idealization of the information.

iv. After learning, it comes the final process, i.e. the updating of memory stores with the newly acquired knowledge. To this aim, CM-elaborated information might be transduced back into a series of biophysical data, compatible with the cellular language of memory storing. If one tries to explain the mechanism underlying this step, she/he might encounter the same difficulties as before (ii) but on the other way around. Conversely, once the information has been converted, the uploading might be easy, just like a file can be uploaded in a folder of a computer. So, every time there is a jump from a psychological environment to a biophysical one or vice-ver$s a$, field properties of our mind are shifted from a Quan- tum mechanics to classic Newtonian mechanics. Though this recurrent shift, it is interesting to note that, by means of memory upgrading, the paradigm memorised here, is that one chosen before in, iii) that can provide the best ACTION on the base of the cause-effect law, given a certain stimulus. Then, TBM enter the circular dynamics shown in Figure 1, always to obeying to Le Chatelier's principle (see above).

\section{CONCLUSIONS}

On the basis of a detailed revision of TBM, novel, interesting inferences that considerably improve the quality of the model, have be conceived; notably, some of the steps driving to COGNITION are mechanistically justified by making reference to quantum mechanics.

The first evidence is that every thought cannot originate from the "nothing" nor by itself. There must always be a trace of information in mind, at least minimal, to start with. A sensory inputs or an information that is transferred by another mind in a manageable form, could trigger the born of a new thought. To understand the overall pathway of a thought one can make an analogy with cell metabolism, i.e. by assuming that all modifications correspond to the flow of the enzyme-catalysed reactions carried out in one specific direction and not on the reverse side because of thermodynamics reasons. An example of this mechanism might be the arousal in each individuals of the existence of a Self, supplied with FW. According to TBM, this thought has been probably ingenerated at the very early stage of individual life; later on, in adulthood, this idea takes deeper and deeper roots in her/his psyche since the first years of life, by means of a repetitive experience of the Ego. According to TBM, the illusion of a FW-equipped Self constitutes the primary idea that underlies the cognitive development of an individual.

At second, there are a series of evidences that provide that mind is deceptive and unprecise, but, above all, is intrinsically dual; so there isn't any absolute truth to be taken on trust. One thing to think about seriously is the general conviction that there must be a unique Reality. This does not mean that the ultimate Reality is not one, but simply it means that it cannot be demonstrated, since that reasoning must pass through our mind. In TBM, the dichotomy between UM and CM is lived by the individual as a dual Realty: 1PP separates a self from the rest of the world; conversely, for 3PP, the duality is virtual. There are not two separated entities in one brain but two cooperating mental functions. According to Eastern atheistic Darśana, mind is fallacious so 1PP and 3PP singly give incomplete and unprecise descriptions of the real. TBM, inspired by this philosophic message, came to the proposal that, 1PP and $3 \mathrm{PP}$ together may have a role in human cognition at least for practical uses.

At third, the mechanism that manage biophysical signals and move them in electrochemical fields, e.g. the phase of TBM mainly corresponding to ACTION, obeys to rules imposed by classic physics; while those functions that explicitly manage ideas and judge situations on the base of a critical sense, e.g. mainly COGNI- 
TION phase, emerge from the collapse of a Quantum-Self with the incoming biophysical information of the ACTION phase. The target of a cognitive process is to obtain an expected outcome from the voluntary action; this expectation is built up on the base of cause-effect relationship, a linear way of thinking typical of classic physics. This relationship is the dualistic way typical of a classic Newtonian field, on the base of which the interactions with the world can be interpreted by a subject; without believing in this relationship, a learning-through experience could never occur.

The intriguing question is how is possible that Quantum-CM may carry out cognitive tasks, trusting on the linear cause-effect relationship, i.e. a classic Newtonian physics. A possible answer can be attributed to the different rates that characterize the quantum and the classic processes: Quantum effects can be measured in fem to seconds while the biophysical signals, i.e. the outcome of the entangled information into a memory content (COGNITION) spans within the millisecond range. This recalls the amazing behaviour that emerges from biophysical computations of the nervous system: Molecular elements, singly investigated, exhibit aleatory behaviour, while, if observed in number, they exhibit a probabilistic-deterministic behaviour. The analogy seems to suggest that fluctuations of every single element in mind are undetermined due to the fast unmeasurable process; though, when many fluctuations are averaged in a sufficiently large time span, a statistically predictable behaviour emerges.

In conclusion, this work has consolidated the overall framework of TBM; the single steps of TBM and the links between them have become more plausible from a rationale point of view and more compatible with the neuro scientific knowledge. Moreover, the possibility that Quantum mechanics may explain some of the transitions underlying TBM's COGNITION, opens the way for a further, interesting debate between past and modern epistemology.

\section{REFERENCES}

1. Libet B, Gleason CA, Wright EW, Pearl DK. Time of conscious intention to act in relation to onset of cerebral activities (readiness-potential): The unconscious initiation of a freely voluntary act. Brain. 1983; 106: 623-642.

2. Libet B. Do we have free will? J Cognitive Studies. 1999; 6: 47-57.

3. Libet B. Mind time: The temporal factor in consciousness. In: Perspectives in Cognitive Neuroscience. Cambridge, MA, USA: Harvard University Press; 2004.

4. Searle JR. The Mistery of Consciousness. The New York Review of Books, New York. USA. 1997.

5. Wegner DM. The Illusion of Conscious Will. W. W. Norton and Company, Cambridge, UK: MIT Press. 2002.
6. Perlovsky L. Free Will. Advances in Cognitive Sciences. 2012; 2: 3237.

7. Dennett DC. The self as the center of narrative gravity. In: Kessel F, Cole PM, Johnson DL, eds. Self and Consciousness: Multiple Perspectives. NJ, USA: LEA Inc. 1992b; 103-114.

8. Bignetti E. Vie sensoriali e soft-brain. Annali della Facoltà di Medicina Veterinaria [In Italian]. University of Parma. 1994; 65-95.

9. Bignetti E. Dissacrazione Della Coscienza [In Italian]. Il Valico Ed. Firenze, Italy. 2001.

10. Bignetti E. Cervello e mente: Ovvero casualità e determinismo. Annali della Facoltà di Medicina Veterinaria[In Italian]. University of Parma. 2003; XXIII: 69-78.

11. Bignetti E. Consciousness can learn but cannot decide. Annali della Facoltà di Medicina Veterinaria[In Italian]. University of Parma. 2004; XXIV: 31-52.

12. Bignetti E. Free will is the illusionary by-product of self-perception. $4^{\text {th }}$ International nonlinear science conference; The Soc. for chaos theory in psychology and life science. March 15-17, 2010; Palermo, Italy.

13. Bignetti E, Ghirri A. Mind and free will. Annali della Facoltà di Medicina Veterinaria[In Italian]. University of Parma. 2010b; XXX: 31-40.

14. Bignetti E. Ego and free will: A virtual binomial apt for cognition. Proc. Neuroplasticity and cognitive modifiability. Medimond Ed. Jerusalem. 2013.

15. Bignetti E. The functional role of free-will illusion in cognition: The Bignetti model. Cognitive Systems Research. 2014; 32: 45-60. doi: 10.1016/j.cogsys.2014.04.001

16. Bignetti E. From brain to mind: A plain route from neurobiology to psychology, Psychol Cogn Sci Open J. 2015; 1: 15-25. doi: 10.17140/PCSOJ-1-103

17. Bignetti E. Which is necessary for Cognition, Free Will or Free Will illusion? Psychol Cogn Sci Open J. 2017; 3(4): 116-122. doi: 10.17140/PCSOJ-3-133

18. O'Connor T, "Free Will", The Stanford Encyclopedia of Philosophy (Summer 2016 Edition), Edward N. Zalta (ed.), Website. https://plato.stanford.edu/archives/sum2016/entries/freewill/.

Accessed. 2016.

19. Bignetti E, Martuzzi F, Tartabini A. A Psychophysical Approach to Test: "The Bignetti Model". Psychol Cogn Sci Open J. 2017; 3(1): 24-35. doi: 10.17140/PCSOJ-3-121 
20. Aimi A, Martuzzi F, Bignetti E. Rational Curves Modeling Psychophysical Tests Data: A Computational Approach Compatible With TBM Cognitive Model. Far East Journal of Mathematical Sciences (FJMS), Allahabad, India. 2018; in press.

21. Spivey M. The Continuity of Mind. Oxford Psychology Series. NC, New York, USA: USA Oxford University Press. 2008.

22. Pouchet B, Save E. Attractors in memory. Science. 2005; 308 : 799-876.

23. Locke J. Essay Concerning Human Understanding (1690), Oxford: Ed. P.H. Nidditch, England, UK: Oxford University Press. 1975.

24. Hume D. A Treatise of Human Nature (1739-1740), Ed. J. A. Selby-Bigge. Oxford, England: Clarendon Press. 1978.

25. Krishnamurti J. Does Free Will Exist? (3rd conversation 1978). (DVD), Brockwood Park, England: Krishnamurti Foundation Trust Ltd. 2003.

26. Jayatilleke KN. Early Buddhist Theory of Knowledge. London: Allen \& Unwin. 1963.

27. Collins S. Selfless Persons: Imagery and Thought in Theravada Buddhism. Cambridge, UK: Cambridge University Press. 1982.

28. Giles J. The No-Self Theory: Hume, Buddhism and Personal Identity. Philosophy East and West. 1993; 43: 175-200.

29. Watts A. Tao: The Watercourse Way. New York, USA: Pantheon book. 1975 .

30. Watts A. The Way of Liberation. New York, USA: Weatherhill Inc. 1983.

31. Watts A. Talking Zen. New York, USA: Weatherhill Inc.1994.

32. Yu-Lan F. A short history of Chinese Philosophy. New York, USA: MacMillan Pub. Co. Inc. 1948.

33. Dennett DC. Elbow Room. Cambridge. MA, USA: MIT Press. 1984.

34. Dennett DC. "My brain made me do if" (when neuroscientists think can do philosophy). Florence: Max Weber Lectures $\left(\mathrm{N}^{\circ}\right.$ 201/01). 2011.

35. Lao Tzu. Tao Te Ching, Milan, Italy: Feltrinelli Ed. (3rd ed). 2013.

36. Liu D. The Tao and Chinese Culture. Abingdon, UK: Routledge \& Kegan P. 1979.

37. Schultz W. Neuronal rewards and decision signals: From the- ories to data, Physiol. Rev. 2015; 95: 853-951. 2014. doi: 10.1152/ physrev.00023

38. White RW. Motivation reconsidered: The concept of competence. Psychol. Rev.1959; 66: 297-333.

39. Barto AG, Singh S, Chentanez N. Intrinsically motivated learning of hierarchical collections of skills., La Jolla. CA., Proc. of the 3rd Intl. Conf. on Developmental Learning. 2004.

40. Pansky A, Nemets E. Enhancing the quantity and accuracy of eyewitness memory via initial memory testing. I Applied Research in Memory and Cognition. 2012; 1: 2-10.

41. Samejima K, Ueda Y, Doya K, Kimura M. Representation of Action-Specific Reward Values in the Striatum, Science. 2005; 310: 1337-1340. doi: 10.1126/science. 1115270

42. Staddon J. On Responsibility and Punishment. The Atlantic Month, Feb. 1995. 88-94.

43. Tolman EC. There is more than one kind of learning. Psychol Rev. 1949a; 56: 144-155.

44. Tolman, Edward C. The nature and function of wants. Psychol Rev. 1949b; 56: 357-369. doi: 10.1037/h0063540

45. Dickinson A, Dawson GR. Motivational control of instrumental performance: The role of prior experience of the reinforcer. Quarterly Journal of Experimental Psychology. 1988; 40B: 113-134.

46. Dickinson A, Dawson GR. Incentive learning and the motivational control of instrumental performance. Quarterly Journal of Experimental Psychology. 1989; 41B: 99-112.

47. Dickinson A. Bolles's psychological syllogism. In M. E. Bouton \& M. S. Fanselow (Eds.), Learning, motivation, and cognition: The functional behaviorism of Robert C. Bolles (pp. 345-367). Washington, DC, US: American Psychological Association. 1997.

48. Ramachandran V. The neurons that shaped civilization, TED Talks. Website. http://www.Ted.Com/Talks/Vs_Ramachandran_ The_Neurons_That_Shaped_Civilization.html. Accessed 2010.

49. Clarke PGH. Neuroscience, quantum indeterminism and the Cartesian soul. Brain \& Cognition. 2014; 84: 109-117. doi: 10.1016/j. bandc.2013.11.008

50. Nichols S. Experimental philosophy and the problem of free will. Science. 2011; 331: 1401-1403. doi: 10.1126/science.1192931

51. Fields-Olivieri MA, Cole PM, Maggi MC. Toddler Emotional States, Temperamental Traits, and their Interaction: Associations with Mothers' and Fathers' Parenting. J. Research in Personality. 2017; 67: 106-119. doi: 10.1016/j.jrp.2016.05.007 
52. Potegal MLP, Davidson RJ. Temper Tantrums in Young Children. J. Developmental \& Behavioral Pediatrics. 2003; 24 (3): 140-147.

53. Aurobindo Shri, Sri Aurobindo Le Yoga de la Bhagavad Gita. Puducherry, India: Sri Aurobindo Ashram Press. 1969.

54. Radhakrishnan S, Indian philosophy (1 and 2). Oxford, UK: Oxford University Press. 1991.

55. Hart WD. Dualism. In: A Companion to the Philosophy of Mind, ed. Samuel Guttenplan, Oxford, UK: Blackwell, 1996: pp. 265-267.

56. Sir Jeans J, Physics and Philosophy. New York, USA: Dover Publications Inc., (republication of 1943 Edition). 1981.

57. Schrodinger E. What is life? The physical aspect of living cells, mind and matter. Cambridge, UK: Cambridge University Press. 1944.

58. Lindlay D. Uncertainty: Einstein, Heisenberg, Bohr, and the Struggle for the Soul of Science. Ends' Well Books Co., Paperback. 2008.

59. Bohm D. Causality and Chance in Modern Physics. London, UK: Routledge, 1957, 1984.

60. Schrodinger E. Indeterminism and Free Will. Nature. 1936; 138: 13-14.

61. Cournot AA. Exposition de la théorie des chances et des probabilités.(1843) In: B. Bru (Ed.) OEuvres complètes [In French]. Tome I, Paris: Vrin. 1998

62. Schroedinger E. Indeterminism and Free Will. Nature. 1936; 1(38): 13-14.

63. Esfeld M. Is Quantum Indeterminism Relevant to Free Will?
Philosophia Naturalis. 2000; 37: 177-187.

64. Schurger A, Sitt JD, Dehaenne S. An accumulator model for spontaneous neural activity prior to self-initiated movement. PNAS. 2012; 109(42): E2904-E2913. doi: 10.1073/pnas.1210467109

65. Peres A. Quantum Theory, Concepts and Methods, Norwell, MA, USA: Kluwer Academic Publishers, 1993.

66. Stapp HP. Mind, Matter and Quantum Mechanics, New York, USA: Berlin-Heidelberg: Springer-Verlag. 2009.

67. Stapp HP. Reply to a critic: Mind efforts, quantum zeno effect and environemental decoherence. Neuro Quantology. 2012; 10: 601605.

68. Chopra D. Quantum Healing (Revised and Updated): Exploring the Frontiers of Mind/Body Medicine. New York, USA: Amazon, paperback. 2015.

69. Bohm D. Wholeness and the implicate order. London: Routledge \& Kegan Paul. 1980.

70. Bohm D. A new theory of the relationship of mind and matter. Philosophical Psychology. 1990; 3: 271-286. doi: 10.1080/09515089008573004

71. Krishnamurti J, Bohm D. The Ending of Time. New York, USA: Amazon, Paperback.1997.

72. Schroedinger E. Die gegenwärtige Situation in der Quantenmechanik. Naturwissenschaften. 1935; 23, 48: 807-812. doi: 10.1007/ BF01491987

73. Searle JR. Consciousness. In Honderich T. The Oxford companion to philosophy. New York, USA: Oxford University Press. 2005.

\section{APPENDIX}

\section{The Bignetti Model (TBM) in 6 compulsory steps:}

\section{ACTION}

(1) The so called "voluntary" action is decided and performed by the agent's UM by means of probabilistic responses to inner and outer stimuli.

(2) After a slight delay, the agent becomes aware of the ongoing action through feedback signals (somatosensory, etc.) that are conveyed to the brain as a consequence of its performance. Thus, the agent's CM always lags behind unconscious activity.

\section{COGNITION}

(3) Owing to this delay, the CM cannot know the unconscious work that precedes awareness; thus the CM erroneously believes it has freely decided the action. Though objectively false, this belief is subjectively perceived astrue (FW illusion). It is so persistent and deep-rooted in the mind that the CM is unwilling to abandon it.

(4) The FW illusion satisfies a psychological need to secure the arousal of the sense of agency (SoA) and of responsibility (SoR) of the action. Both SoA and SoR inevitably lead the CM to self-attribute reward or blame depending on action performance and outcome.

(5) Both reward and blame are motivational incentives that foster learning and memory in the CM;

(6) The updating of knowledge in short and long-term memory (experience's gain) will provide new information and the skill required for further action (restart from point (1)) as shown in Figure 1 